\title{
Interaction Diagram of Rubberised Concrete Filled Circular Hollow Sections
}

\author{
Mohamed Elchalakani, Minhao Dong, Ali Karrech \\ School of Civil, Environmental and Mining Engineering, The University of Western Australia, WA 6009, \\ Australia \\ E-mail:mohamed.elchalakani@uwa.edu.au,minhao.dong@uwa.edu.au,ali.karrech@uwa.edu.au
}

Received: 5 September 2018; Accepted: 26 September 2018; Available online: 15 January 2019

\begin{abstract}
Concrete filled steel tube (CFST) is increasingly used in engineering construction as columns and beams. CFST is known to absorb large amounts of energy as a result of the composite effect. Internationally, there are increasing amounts of waste rubber. In this study recycled rubber is used as aggregate supplement in concrete. Rubberised concrete is known to be more ductile than conventional concrete however has a lower compressive strength. This study investigated the performance of thirty rubberised concrete-filled single-skin steel tubes under combined loading conditions and compared the results against six steel hollow tubular members. Three rubber replacement ratios, $0 \%, 15 \%$ and $30 \%$, three load eccentricities and four tube sections with section slenderness (b/t, width/thickness) of 18 to 36 were examined. The results have shown that the composite section had greatly improved load carrying capacity. The ductile rubberised concrete was more effective in delaying the premature buckling failure of the steel tube compared to the normal concrete. The interaction diagrams were constructed from the experiments and theoretical calculations. It was found that the behaviours of the rubberised concrete filled steel tubes could be accurately predicted using existing design guidelines. This study demonstrated the potential of using rubberised concrete as a cost-effective solution to safe roadside barriers and structural members in buildings located in seismic active zones.
\end{abstract}

Keywords: Rubberised concrete; Concrete-Filled single-skin tubes; Combined loading; Interaction diagram.

\section{Introduction}

Concrete filled steel tubes (CFST) are increasingly used in engineering construction as columns and beams. The concrete provides restraint to buckling of the steel tube therefore increasing its strength and ductility. Additionally, the steel tube provides confinement of the concrete increasing its strength. As a result of the composite effect CFST can absorb large amounts of energy [1].

In Australia and internationally there are increasing amounts of waste rubber being generated. It is an environmental, health and fire hazard, and costs millions of dollars to dispose every year [2,3]. As such there is a growing need for uses of recycled rubber [4-6]. One use is rubber as aggregate in concrete. The rubberised concrete $(\mathrm{RuC})$ has improved mechanical properties such as ductility, fracture toughness and energy absorption compared to the normal concrete $(\mathrm{NC})$, however with reduced compressive strength and stiffness. Limited progress has been made to improve the mechanical strength of RuC [7]. To mitigate the significant reduction in strength, steel tubes may be filled with rubberised concrete to form rubberised concrete filled steel tubes (RuCFST). The confinement of the rubberised concrete increases its strength in the same way as standard concrete. Confined rubberised concrete has high ductility and as such it can maintain its strength after yielding unlike standard concrete.

Over the past few decades, research has investigated single and double skin CFST [8]. In recent decades, design specifications for CFST have been included in design codes such as Eurocode 4 and CIDECT 4 [9,10]. The use of CFST in engineering construction has also been increasing. By comparison, there is very little understanding of RuCFST. In particular there is a lack of knowledge relating to the behaviour of RuCFST under combined loading.

\section{Experimental program}

Three mixes were compared in this study, namely NC (normal concrete), RuC15, RuC30 to denote the replacement ratios of rubber particles to aggregates. The binder material is the general purpose ordinary Portland cement. The $2-5 \mathrm{~mm}$ crumb rubber was suitable to partially replace $<4 \mathrm{~mm}$ aggregates whereas $5-7 \mathrm{~mm}$ chip rubber was suitable to replace $7 \mathrm{~mm}$ coarse aggregate. The crumb and chip rubber used in this study were treated with 
$10 \%$ sodium hydroxide $(\mathrm{NaOH})$ solution for 24 hours to increase bonding with cement matrix and increase its specific weight [11]. The mix proportions of the three concrete mixes are shown in Table 1. A water to cement ratio of 0.48 was adopted for all three mixes to ensure satisfactory workability.

Table 1. Mix proportions of NC, RuC15 and RuC30

\begin{tabular}{|c|c|c|c|c|c|c|c|c|c|}
\hline Mix & $\begin{array}{c}\text { Water } \\
\left(\mathrm{kg} / \mathrm{m}^{3}\right)\end{array}$ & $\begin{array}{l}\text { Cement } \\
\left(\mathrm{kg} / \mathrm{m}^{3}\right)\end{array}$ & $\begin{array}{c}\text { Fine } \\
\text { aggregate } \\
\left(\mathrm{kg} / \mathrm{m}^{3}\right)\end{array}$ & $\begin{array}{c}10 \mathrm{~mm} \\
\text { coarse } \\
\text { aggregate } \\
\left(\mathrm{kg} / \mathrm{m}^{3}\right)\end{array}$ & $\begin{array}{c}7 \mathrm{~mm} \\
\text { coarse } \\
\text { aggregate } \\
\left(\mathrm{kg} / \mathrm{m}^{3}\right)\end{array}$ & $\begin{array}{c}<4 \mathrm{~mm} \\
\text { Coarse } \\
\text { aggregate } \\
\left(\mathrm{kg} / \mathrm{m}^{3}\right)\end{array}$ & $\begin{array}{l}\text { 7-10 mm } \\
\text { rubber } \\
\text { chip } \\
\left(\mathrm{kg} / \mathrm{m}^{3}\right)\end{array}$ & $\begin{array}{c}2-5 \mathrm{~mm} \\
\text { rubber } \\
\text { crumb } \\
\left(\mathrm{kg} / \mathrm{m}^{3}\right)\end{array}$ & $\begin{array}{c}\text { Concrete } \\
\text { compressi } \\
\text { ve } \\
\text { strength } \\
f_{c}^{\prime}(\mathrm{MPa})\end{array}$ \\
\hline $\mathrm{NC}$ & 205 & 426 & 843 & 444 & 306 & 130 & 0 & 0 & 40.8 \\
\hline RuC15 & 205 & 426 & 648 & 311 & 214 & 91 & 45 & 58 & 17.9 \\
\hline RuC30 & 205 & 426 & 453 & 178 & 122 & 52 & 90 & 117 & 9.5 \\
\hline
\end{tabular}

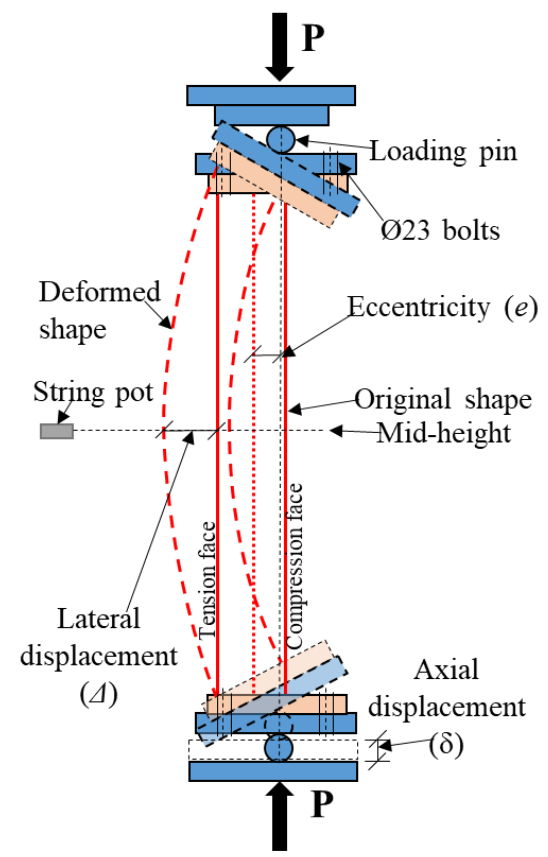

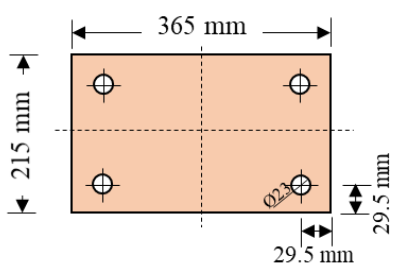

Base plate

(a) CFST columns

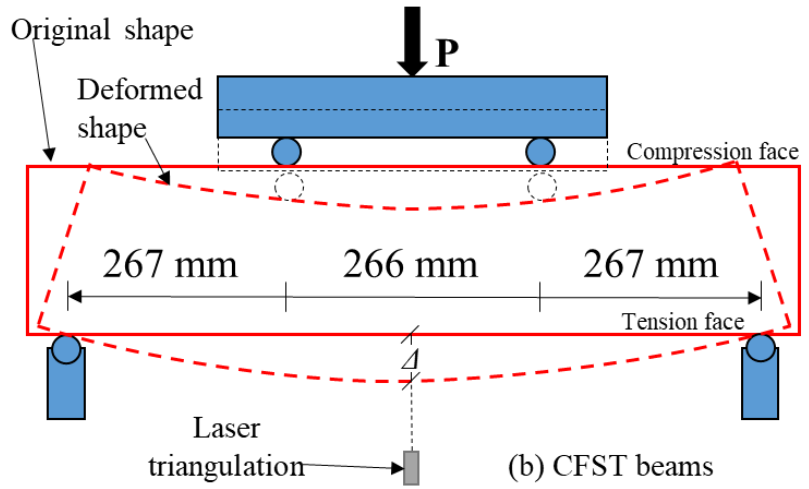

Fig. 1 Test setup for (a) CFST columns, and (b) CFST beams

Four grade C350L0 cold-formed circular steel sections were used for CFST beams and columns. In total, the behaviours of 18 CFST columns ( 2 sections, 3 types of concrete and 3 load eccentricities) and 12 CFST beams ( 4 sections and 3 types of concrete) were investigated. The specimen designation followed steel tube depth-steel tube thickness-load eccentricity (or "F" for the flexural tests)-rubber replacement ratio. "CFT" was used to represent concrete filled tube composite sections and "CHS" represented hollow circular hollow section (CHS) members. The details of the CHS tubes, including slenderness classifications from AS 4100 [12] and comparison to the provisions in Eurocode 3 [13] are shown in Table 2. The composite specimens were covered with plastic sheet to limit drying shrinkage and cured for one month at ambient room temperature inside the Structural Laboratory at University of Western Australia. 
Table 2. Details of the CHS tubes

\begin{tabular}{|c|c|c|c|c|c|c|c|c|c|}
\hline Section & $\begin{array}{l}\text { Depth } \\
\quad d \\
(\mathrm{~mm})\end{array}$ & $\begin{array}{c}\text { Thickness } \\
t \\
(\mathrm{~mm})\end{array}$ & $\begin{array}{c}\text { Area } \\
\text { of } \\
\text { steel } \\
A_{s} \\
\left(\mathrm{~mm}^{2}\right)\end{array}$ & $\begin{array}{c}\text { Area of } \\
\text { concrete } \\
A_{c} \\
\left(\mathrm{~mm}^{2}\right)\end{array}$ & $\begin{array}{c}\text { Section } \\
\text { Slenderness } \\
b / t\end{array}$ & $\begin{array}{c}\text { Section } \\
\text { Slenderness } \\
\frac{d}{t} \frac{f_{y}}{250} \\
\text { AS } 4100 \\
{[12]}\end{array}$ & $\begin{array}{c}\text { Section } \\
\text { Slenderness } \\
\frac{d}{t} \frac{f_{y}}{235} \\
\text { Eurocode } 3 \\
{[13]}\end{array}$ & $\begin{array}{c}\text { Section } \\
\text { Slenderness } \\
\text { AS4100 } \\
{[12]}\end{array}$ & $\begin{array}{c}\text { Section } \\
\text { Slendern } \\
\text { ess } \\
\text { Eurocode } \\
3 \\
{[13]}\end{array}$ \\
\hline CHS89×5 & 88.9 & 5 & 1318 & 4889 & 18 & 25 & 26 & Compact & Class 1 \\
\hline CHS $89 \times 3.2$ & 88.9 & 3.2 & 862 & 5346 & 28 & 39 & 41 & Compact & Class 1 \\
\hline CHS114×3.6 & 114.3 & 3.6 & 1252 & 9009 & 32 & 44 & 47 & Compact & Class 1 \\
\hline CHS114×3.2 & 114.3 & 3.2 & 1117 & 9144 & 36 & 50 & 53 & Non-compact & Class 2 \\
\hline
\end{tabular}

The CFST columns were subjected to concentric and eccentric loading by a $600 \mathrm{kN}$ Baldwin machine through a displacement-control regime. The test setups for columns and beams are demonstrated in Fig. 1. The load eccentricity was applied through the distance between the centre of the base place and the centre of the column. Four-point bending tests were adopted to measure the flexure strength of the CHS tubes and CFST beams. Each specimen was setup on the Baldwin compression machine with $100 \mathrm{~mm}$ overhanging segments from each end of the beam and $267 \mathrm{~mm}$ distance between each loading/support points.

\section{Results and discussion}

\subsection{Load carrying capacity}

The 28-day compressive strengths for NC, RuC15 and RuC30 were 40.8, 17.9 and 9.5 MPa, respectively. The significant strength reduction by rubber replacement was observed, with $15 \%$ rubber replacement reducing the strength by $56 \%$ and $30 \%$ replacement by $77 \%$, respectively.

The test results and the calculated concrete contribution of the 36 concrete filled and hollow tubular specimens are shown in Table 3. The concrete contribution was calculated with respect to the load capacities of the corresponding hollow tube results. Overall, the concrete infill significantly improved the load carrying capacity of the hollow tubes by effectively delaying the buckling failure. A lower rubber replacement ratio was seen to correspond to higher load capacity due to higher strength of the encased concrete. Higher load capacity was also seen for the columns loaded at lower load eccentricity due to the lower moment. A more compact cross-section would also correspond to a greater load carrying capacity due to the better confinement it provided to the concrete infill and its lower tendency to buckle. On average, the RuC15 and RuC30 filled steel tubes were 9.3\% and $19.1 \%$ weaker, respectively, than those filled with the much stronger NC. This showed RuCFST had adequate strength to be adopted as structural members.

\subsection{Interaction diagrams}

The interaction diagrams of concrete filled CHS89×3.2 and CHS114×3.6 specimens were constructed in accordance to Eurocode 4 [9] and CIDECT [10]. Four points were obtained for each interaction curve. At pure compression (Point $\mathrm{A}$ ), $\mathrm{M}_{\mathrm{A}}=0$ and $\mathrm{N}_{\mathrm{A}}$ is calculated from eq. 1 .

$$
N_{A}=N_{p l, R d}=A_{c} f_{c}^{\prime}+A_{s} f_{y}
$$

At pure bending (Point B) from Eurocode 4 [9], $\mathrm{N}_{\mathrm{B}}=0$ and $\mathrm{M}_{\mathrm{B}}$ was obtained from eq. 2. $\alpha_{c}$ was taken as 1 to account for the confinement provided by the steel tube.

$$
M_{B}=M_{p l, R d}=\left(W_{p a}-W_{p a, n}\right) f_{y}+0.5\left(W_{p c}-W_{p c, n}\right) \alpha_{c} f_{c}
$$

Where

$$
W_{p c}=\frac{(d-2 t)^{3}}{6} ; W_{p a}=\frac{d^{3}}{6}-W_{p c} ; W_{p c, n}=(d-2 t) h_{n}^{2} ; W_{p a, n}=d h_{n}^{2}-W_{p c, n}
$$

and

$$
h_{n}=\frac{A_{c} f_{c}^{\prime}}{2 d f_{c}^{\prime}+4 t\left(2 f_{y}-f_{c}^{\prime}\right)} .
$$


Table 3. Test results of the 36 concrete filled and hollow tubular columns and beams

\begin{tabular}{|c|c|c|c|}
\hline Specimen & Load $(\mathrm{kN})$ & Concrete contribution $\Delta \mathrm{Pc}(\mathrm{kN})$ & Concrete contribution $\% \Delta \mathrm{Pc}$ \\
\hline CHS $89 \times 3.2-\mathrm{F}$ & 87 & - & - \\
\hline CFT $89 \times 3.2-F-0$ & 124 & 37 & $42 \%$ \\
\hline CFT $89 \times 3.2-F-15$ & 114 & 27 & $31 \%$ \\
\hline CFT $89 \times 3.2-F-30$ & 112 & 25 & $28 \%$ \\
\hline CHS $89 \times 5-\mathrm{F}$ & 122 & - & - \\
\hline CFT $89 \times 5-\mathrm{F}-0$ & 153 & 31 & $25 \%$ \\
\hline CFT89×5-F-15 & 146 & 24 & $20 \%$ \\
\hline CFT89×5-F-30 & 139 & 16 & $13 \%$ \\
\hline CHS114×3.2-F & 128 & - & - \\
\hline CFT114×3.2-F-0 & 197 & 69 & $54 \%$ \\
\hline CFT114×3.2-F-15 & 183 & 55 & $43 \%$ \\
\hline CFT114×3.2-F-30 & 179 & 51 & $40 \%$ \\
\hline CHS114×3.6-F & 171 & - & - \\
\hline CFT114×3.6-F-0 & 252 & 82 & $48 \%$ \\
\hline CFT114×3.6-F-15 & 233 & 62 & $36 \%$ \\
\hline CFT114×3.6-F-30 & 219 & 49 & $29 \%$ \\
\hline CHS $89 \times 3.2-0$ & 316 & - & - \\
\hline CFT89×3.2-0-0 & 616 & 299 & $95 \%$ \\
\hline CFT $89 \times 3.2-0-15$ & 512 & 196 & $62 \%$ \\
\hline CFT $89 \times 3.2-0-30$ & 414 & 98 & $31 \%$ \\
\hline CFT89×3.2-22-0 & 312 & - & - \\
\hline CFT89×3.2-22-15 & 227 & - & - \\
\hline CFT89×3.2-22-30 & 195 & - & - \\
\hline CFT $89 \times 3.2-45-0$ & 195 & - & - \\
\hline CFT $89 \times 3.2-45-15$ & 149 & - & - \\
\hline CFT $89 \times 3.2-45-30$ & 135 & - & - \\
\hline CHS114×3.6-0 & 520 & - & - \\
\hline CFT114×3.6-0-0 & 1001 & 482 & $93 \%$ \\
\hline CFT114×3.6-0-15 & 854 & 334 & $64 \%$ \\
\hline CFT114×3.6-0-30 & 667 & 148 & $28 \%$ \\
\hline CFT114×3.6-29-0 & 472 & - & - \\
\hline CFT114×3.6-29-15 & 385 & - & - \\
\hline CFT114×3.6-29-30 & 323 & - & - \\
\hline CFT114×3.6-57-0 & 293 & - & - \\
\hline CFT114×3.6-57-15 & 266 & - & - \\
\hline CFT114×3.6-57-30 & 226 & - & - \\
\hline
\end{tabular}

The Point B from CIDECT [10] was defined as Eq. 3, which required to obtain a coefficient mo for CHS.

$$
\mathrm{M}_{\mathrm{pl}, \mathrm{Rd}}=\mathrm{m}_{\bigcirc} \frac{\mathrm{h}^{3}-(\mathrm{d}-2 \mathrm{t})^{3}}{6} \mathrm{f}_{\mathrm{y}}
$$

Point $\mathrm{C}$ and Point $\mathrm{D}$ formed an equilateral triangle on the interaction diagram. The moment at Point $\mathrm{C}$ was the same as that at Point B, however its load was defined as eq. 4.

$$
N_{c}=N_{p m, R d}=A_{c} \alpha_{c} f_{c}^{\prime}
$$

At Point D, the load is half of that at Point $\mathrm{C}$ and the moment was at the maximum (eq. 5).

$$
M_{D}=M_{\max , R d}=W_{p a} f_{y}+0.5 W_{p c} \alpha_{c} f_{c}^{\prime}
$$

The interaction diagrams of concrete filled CHS89 $\times 3.2$ and CHS114 $\times 3.6$ specimens constructed from the experimental results and theoretical calculations by Eurocode 4 [9] and CIDECT [10] are shown in Fig. 2 and 3, respectively. Overall, the constructed theoretical interaction curves showed acceptable agreements to the experimental results. Safe design could be produced for RuC filled less compact sections, i.e. CHS114 $\times 3.6$ with $d / t=32$. The "balance point" D shifted inwards and the distance between Point C and Point B decreased as the concrete compressive strength reduced. This was due to the limited contribution of concrete as the moment increased. The interaction diagram tended to a straight line and shifted inwards as the steel contribution increased, as shown by the increasing $\mathrm{A}_{\mathrm{s}} \mathrm{f}_{\mathrm{y}} / \mathrm{N}_{\mathrm{pl}, \mathrm{Rd}}$ values in the figures. 

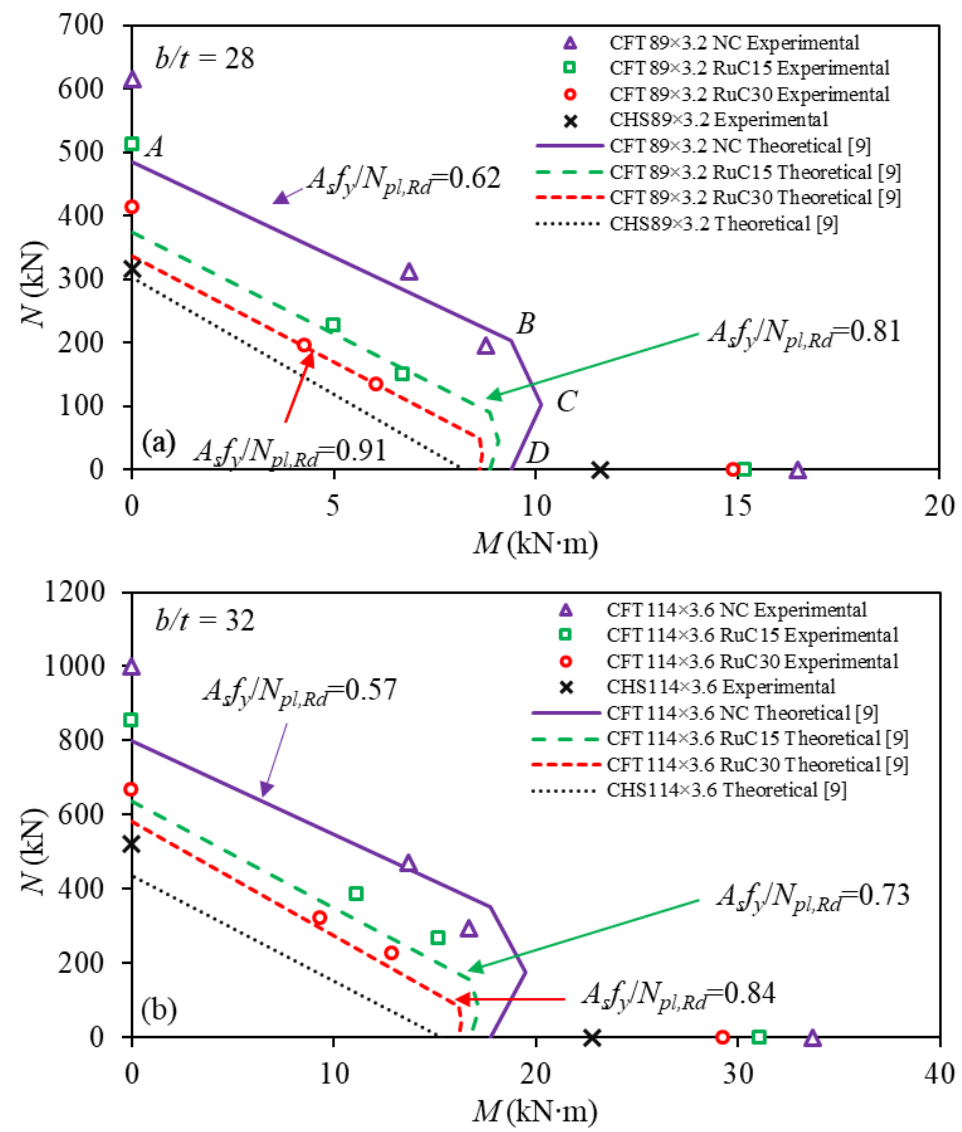

Fig. 2 The comparison between the experimental results and the analytical interaction diagram [9] of concrete filled (a) CHS89×3.2 and (b) CHS114×3.6 specimens

In Fig. 2a, the measured load carrying capacity of the concentrically loaded concrete filled CHS $89 \times 3.2$ beams were underestimated by Eurocode 4 [9] by an average $31.9 \%$. This was due to the compact section provided better confinement to the concrete core and was less prone to local buckling failure. As the load eccentricity increased, the safety margin reduced significantly and became unsafe from a design point of view. This was especially noticeable for NC filled columns. The brittle NC infill failed prematurely due to the large deformation and was unable to deform sufficiently to fill the buckle of the steel tube. The more ductile $\mathrm{RuC}$ infill was more effective in delaying the buckling failure due to the larger deformation capacity. The moment capacities of the CFST beams obtained from four-point bending tests greatly exceeded the predictions by Eurocode 4 [9]. The exceptional moment capacity of the RuCFST beams showed the potential to be used as flexible roadside barriers.

In Fig. 2b, the concentrically loaded columns confined by the non-compact CHS114×3.6 again exceeded the theoretical predictions by an average $21.6 \%$. The safety margin was lower than concrete filled CHS $89 \times 3.2$ due to the lower slenderness, which in turn was less effective in delaying the local buckling of the steel tube. The average safety margin was lower for eccentrically load columns, similar to concrete filled CHS $89 \times 3.2$ columns. However, the design of RuC filled members were still safe by a satisfactory margin. The beams with CHS114×3.6 failed in bending, resulting in much higher $(85.8 \%)$ moment capacities than the theoretical calculations. As a comparison, the safety margin for concrete filled CHS $89 \times 3.2$ beams was $73.3 \%$.

Fig. 3 showed the interaction diagram constructed in accordance to CIDECT [10]. It is slightly less conservative compared to Eurocode 4 [9] in terms of moment capacities for the more slender CHS114 $\times 3.6$. Similarly, the concentrically loaded CFST columns and CFST beams greatly exceeded the predicted capacities, showing the effectiveness of using the RuC as a cost-effective infill.

Fig. 4 shows the normalised interaction diagram of the experimental results of the 24 concrete filled CHS $89 \times 3.2$ and CHS114 $\times 3.6$ specimens. The load and moment were normalised by the load and moment capacities of their respective circular hollow tubes. Larger improvement over the hollow tubes was observed for the concrete filled CHS114×3.6. CHS114×3.6 was more prone to buckling due to its larger section slenderness, therefore the effect of the concrete infill on delaying such failure was more noticeable. This was especially seen for the eccentrically loaded columns under combined moment and axial load. The difference between RuC and $\mathrm{NC}$ reduced as the load eccentricity increased, and was at the minimum under flexural loading. This was due to the limited contribution 
of concrete as the concrete stress block shrunk in size. RuCFST had comparable performance in bending to NC, while being more environmentally-friendly and cost-effective. RuCFST beams could be used as safe roadside barriers to replace the current concrete or hollow tubular roadside barriers.
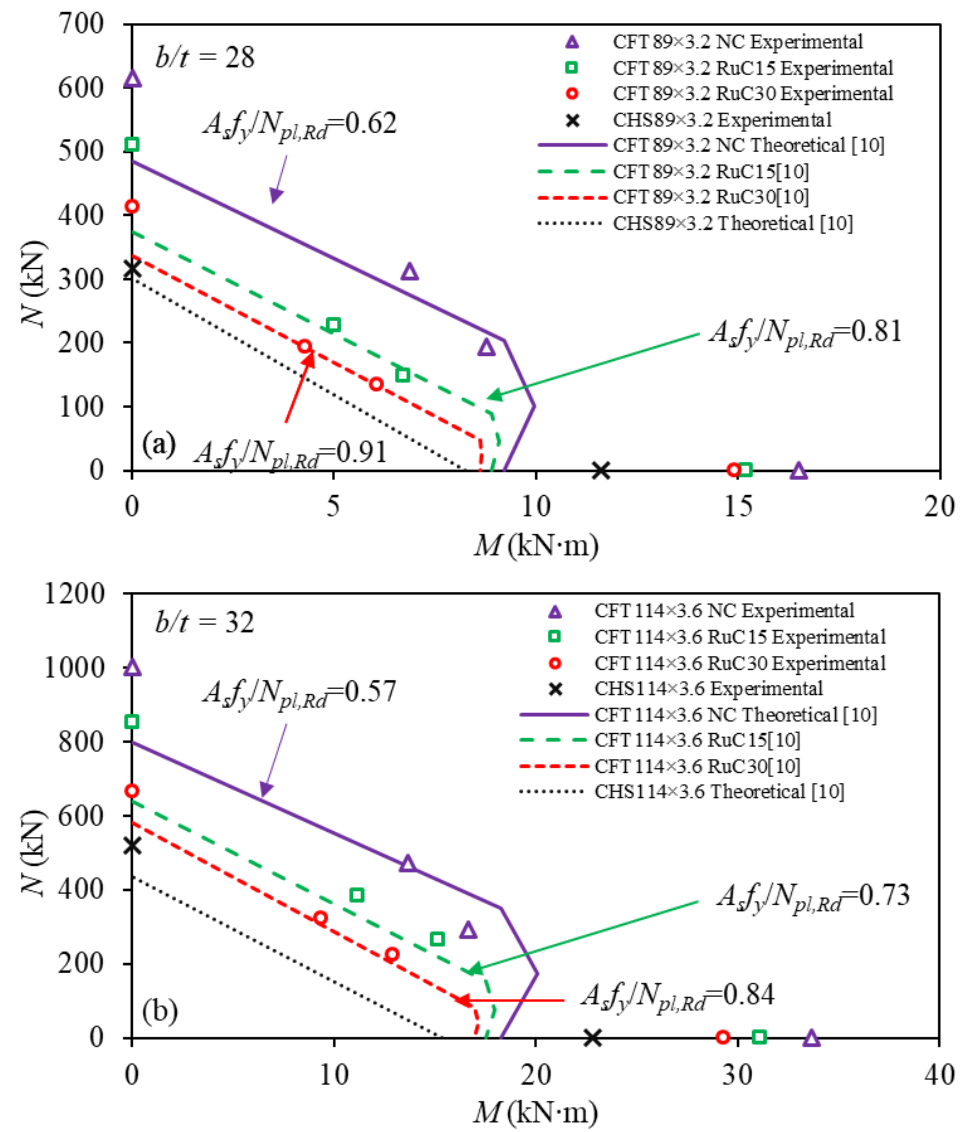

Fig. 3 The comparison between the experimental results and the analytical interaction diagram [10] of concrete filled (a) CHS89×3.2 and (b) CHS114×3.6 specimens

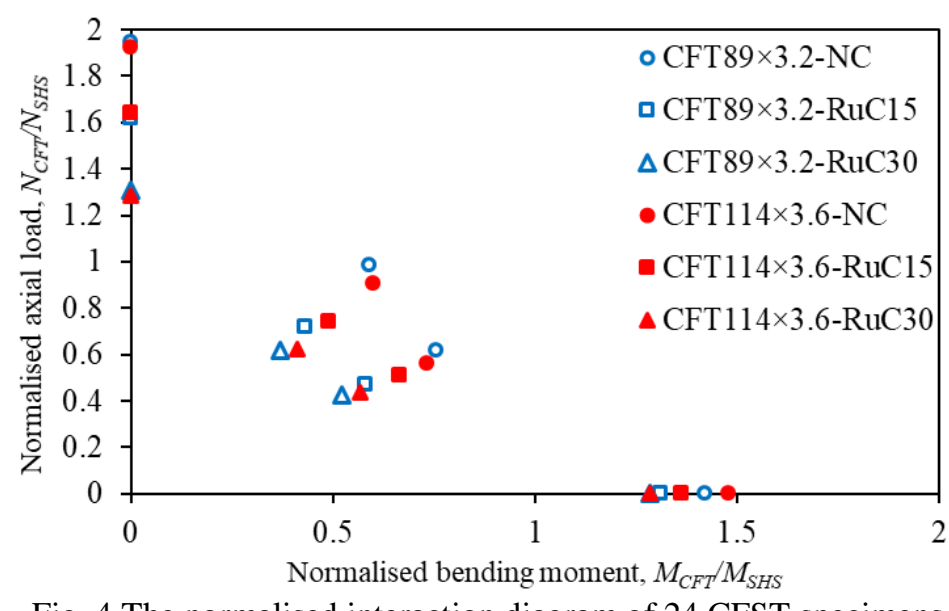

Fig. 4 The normalised interaction diagram of 24 CFST specimens

\section{Conclusions}

Thirty circular CFST specimens with $0 \%, 15 \%$ and 30\% rubber replacement ratios and 4 different steel sections were tested under axial, flexural and combined loading conditions. The following conclusions could be drawn:

1) Significant strength reduction was observed in RuC. 
2) The strength reduction of rubber replacement could be mitigated by confinement through a steel tube. The $\mathrm{RuC}$ was effective in delaying the premature buckling of the composite section, which corresponded to the larger safety margin over the predicted values in the design guides. They could be used cost-effectively as structural members.

3) The RuCFST beams showed more than $70 \%$ increments on average compared to the theoretical predictions, which showed the possibility of using RuCFST as flexible roadside barriers.

\section{Acknowledgements}

The authors would like to deeply thank Liam O'keefe from Tyres Stewardship Australia and Adrian Jones from Tyrecycle. Thanks are given to Andrew Sarkady and Anup Chakrabortty from BASF for kindly donating the superplasticizer required for all the specimens. Thanks are given the following technicians Matt Arpin, Malcolm Stafford, Jim Waters and Brad Rose for assisting the students in performing the experiments. Thanks are given to William Richards and Qing Zhu, students of UWA for performing the tests and processing the test data.

\section{References}

[1] Morino S, Uchikoshi M, Yamaguchi I. Concrete-filled steel tube column system-its advantages. Steel Struct. $2001 ; 1: 33-44$.

[2] Elchalakani M, Aly T, Abu-Aisheh E. Mechanical properties of rubberised concrete for road side barriers. Aust J Civ Eng. 2016;14:1-12. doi:10.1080/14488353.2015.1092631.

[3] Elchalakani M. High strength rubberised concrete contains silica fumes for the construction of sustainable roadside barriers. Int J Struct. 2015;1:10-28.

[4] Duarte APC, Silva BA, Silvestre N, de Brito J, Júlio E, Castro JM. Tests and design of short steel tubes filled with rubberised concrete. Eng Struct. 2016;112:274-286. doi:10.1016/j.engstruct.2016.01.018.

[5] Elchalakani M, Hassanein MF, Karrech A, Yang B. Experimental investigation of rubberised concrete- filled double skin square tubular columns under axial compression. Eng Struct. 2018;171:730-746. doi:10.1016/j.engstruct.2018.05.123.

[6] Xue J, Shinozuka M. Rubberized concrete: A green structural material with enhanced energy-dissipation capability. Constr Build Mater. 2013;42:196-204. doi:10.1016/j.conbuildmat.2013.01.005.

[7] Najim KB, Hall MR. A Review of the Fresh/hardened Properties and Applications for Plain- (PRC) and Selfcompacting Rubberised Concrete (SCRC). Constr Build Mater. 2010;24:2043-2051.

[8] Han LH, Li W, Bjorhovde R. Developments and advanced applications of concrete-filled steel tubular (CFST) structures: Members. J Constr Steel Res. 2014;100:211-228. doi:10.1016/j.jcsr.2014.04.016.

[9] EN 1994-1-1. Eurocode 4 : Design of composite steel and concrete structures Part 1-1: General rules and rules for buildings 2004:1-127. doi:10.1680/dgte4.31517.

[10] CIDECT. Design guide for concrete filled hollow section columns under static and seismic loading. 1995.

[11] Segre N, Joekes I. Use of tire rubber particles as addition to cement paste. Cem Concr Res. 2000;30:14211425. doi:10.1016/S0008-8846(00)00373-2.

[12] AS 4100. Steel structures. 2nd ed. Standards Australia; 1998.

[13] EN 1993-1-1. Eurocode 3: Design of steel structures - Part 1-1: General rules and rules for buildings. 2005.[Authority: The European Union Per Regulation 305/2011, Directive 98/34/EC, Directive 2004/18/EC].

(C) 2019 by the author(s). This work is licensed under a Creative Commons Attribution 4.0 International License (http://creativecommons.org/licenses/by/4.0/). Authors retain copyright of their work, with first publication rights granted to Tech Reviews Ltd. 